\title{
Effect of Aging in the Perception of Health-Related Quality of Life in End-Stage Renal Disease Patients under Online-Hemodiafiltration
}

\author{
Alexandra Moura ${ }^{1}$, José Madureira ${ }^{2}$, Pablo Alija ${ }^{2}$, João Carlos Fernandes ${ }^{3}$, José Gerardo \\ Oliveira $^{4}$, Martin Lopez ${ }^{5}$, Madalena Filgueiras ${ }^{6}$, Leonilde Amado ${ }^{7}$, Maria Sameiro-Faria ${ }^{7}$, Vasco \\ Miranda $^{7}$, Alice Santos-Silva ${ }^{8,9}$, Elísio Costa ${ }^{8,9 *}$ \\ ${ }^{1}$ Instituto de Ciências da Saúde, Universidade Católica Portuguesa, Porto, Portugal; ${ }^{2}$ Clínica de Hemodiálise \\ NefroServe, Barcelos, Portugal; ${ }^{3}$ Clínica de Hemodiálise NefroServe, Viana do Castelo, Portugal; ${ }^{4}$ Centro \\ Hospitalar do Porto, Porto, Portugal; ${ }^{5}$ Clínica de Hemodiálise de Felgueira, Felgueiras, Portugal; ${ }^{6}$ Clínica de \\ Hemodiálise de Gondomar, Gondomar, Portugal; ${ }^{7}$ Clínica de Hemodiálise NephroCare, Maia, Portugal; \\ ${ }^{8}$ Laboratório de Bioquímica, Departamento de Ciências Biológicas, Faculdade de Farmácia, Universidade do \\ Porto, Portugal; ${ }^{9}$ Instituto de Biologia Molecular e Celular, Universidade do Porto, Portugal.
}

[Received February 9, 2014; Revised May 13, 2014; Accepted May 14, 2014]

\begin{abstract}
This work aimed to evaluate how aging could influence patients' perception of health quality of life (HRQOL), as well as, the effect of aging on dialysis adequacy and in hematological, iron status, inflammatory and nutritional markers. In this transversal study were enrolled 305 ESRD patients under online-hemodiafiltration (OL-HDF) $(59.67 \%$ males; $64.9 \pm 14.3$ years old). Data about comorbidities, hematological data, iron status, dialysis adequacy, nutritional and inflammatory markers were collected from patient's records. Moreover, HRQOL score, by using the Kidney Disease Quality of Life-Short Form (KDQOL-SF), was assessed. Analyzing the results according to quartiles of age, significant differences were found for some parameters evaluated by the KDQOL-SF instrument, namely for work status, physical functioning and role-physical, which decreased with increasing age. We also found a higher proportion of diabetic patients, a decrease in creatinine, iron, albumin serum levels, transferrin saturation and nPCR, with increasing age. Moreover, significant negative correlations were found between age and mean cell hemoglobin concentration, iron, transferrin saturation, albumin, nPCR, work status, physical functioning and role-physical. In conclusion, our results showed that aging is associated with a decreased work status, physical functioning and role-physical, with a decreased dialysis adequacy, iron availability and nutritional status, and with an increased proportion of diabetic patients and of patients using central venous catheter, as the vascular access. The knowledge of these changes associated with aging, which have impact in the quality of life of the patients, could be useful in their management.
\end{abstract}

Key words: Health-related quality of life, on-line hemodiafiltration, aging, gender, dialysis adequacy, iron availability, nutritional status

End-stage renal disease (ESRD) patients present high mortality rate $[1,2]$ that far exceeds the mortality rate for the general population [3]. In the past half century, the widespread use of dialysis to prolong life of ESRD patients has been a remarkable achievement, preventing death from uremia in these patients. Nowadays, this therapy has expanded widely and is particularly used by an increased elderly population, leading to significant economic consequences to patients and to healthcare systems. Although some evidence may suggest that mortality rate among dialysis patients have decreased over the last few years, actually, patient's survival is still low. 
Cardiovascular diseases (CVD) are the most common cause of death in these patients [4].

Dialysis presents a considerable negative impact on the functional status and in the health-related quality of life (HRQOL) of ESRD patients, as perceived by the patients. Dialysis is associated to symptoms that affect the daily life of the patients, and there is growing evidence that patients give more importance to the HRQOL than to survival [5]. Moreover, recent reports have shown that questionnaire-derived assessment of HRQOL is a strong and independent predictor of mortality and morbidity in ESRD patients [6-8]. For instance, the Dialysis Outcomes and Practice Patterns Study (DOPPS) concluded that a value lower than 10-points in Physical Component Summary of SF-36 was associated with a higher mortality risk, as compared to the risk associated to a albumin serum level lower than $1 \mathrm{~g} / \mathrm{dL}$ [9].

Dialysis is the most important replacement therapy to prolong life of ESRD patients. In the last years, online hemodiafiltration (OL-HDF) technique has been introduced as an alternative to the classical hemodialysis (HD) procedure, which may reduce the risk of morbidity and mortality of ESRD patients [10,11]. In fact, a reduction of $30 \%$ in all-cause mortality, of $33 \%$ in cardiovascular mortality, and of 55\% in risk of infectionrelated mortality, has been described in OL-HDF patients, when compared with those on conventional high-flux HD [12]. However, other studies [13] showed similar morbidity and mortality risk values for both dialysis techniques.

Currently, a higher proportion of dialysis patients are old, raising a major challenge to health care systems [14], as they usually show a high number of comorbidities, the functional status is poor, the prevalence of depression is high and they often avoid personal involvement [15]. However, there is a lack of information about the effect of aging in HRQOL, and in clinical and analytical characteristics of dialysis patients. By this reason, we aimed to evaluate how age could influence patients' perception of HRQOL. Moreover, we also aimed to evaluate the effect of aging on dialysis adequacy and in hematological, iron status, inflammatory and nutritional markers.

\section{MATERIAL AND METHODS}

\section{Patients and study design}

A descriptive transversal observational study was conducted to assess the HRQOL in ESRD patients on OLHDF, by using Kidney Disease Quality of Life-Short Form (KDQOL-SF) instrument, in order to study the impact of age on HRQOL. Patients were grouped into four categories based on age quartiles, the first quartile included patients with less than 56 years old $(n=77)$, the second quartile included patients between 57 to 68 years old $(\mathrm{n}=86)$, the third quartile included patients between 69 and 75 years old $(n=70)$, and the last quartile included patients with more than 75 years old $(n=72)$.

This work had the collaboration of five dialysis units from the north of Portugal. A total of 305 patients $(59.67 \%$ males), with a mean $( \pm \mathrm{SD})$ age of $64.9 \pm 14.3$ years old, was evaluated. Patients were under therapeutic dialysis three times per week for the duration of 3-5 hours each session. The main causes of renal failure, in our group of patients, were diabetic nephropathy $(\mathrm{n}=116)$, hypertensive nephrosclerosis $(\mathrm{n}=45)$, other diseases or uncertain etiology $(\mathrm{n}=144)$.

For OL-HDF procedure, Fresenius Medical Care dialysis machines (model 5008) and synthetic high-flux polysulfone dialyzers (Fresenius Medical Care, Bad Hamburg, Germany) were used. Patients were excluded if they were under 18 years old, cognitively impaired, had a severe speech or hearing impairment, malignancy, autoimmune disease, inflammatory or infectious diseases, and if they were in the dialysis program for less than three month.

At starting the study, the patients were clinically evaluated and blood samples were collected for analytical evaluation; KDQOL-SF questionnaire was selfadministered to all patients. This survey collected data on age, gender, time under dialysis, etiology of kidney disease, hematological data, iron status, inflammatory and nutritional markers, as well as data on dialysis adequacy, from patient records. Laboratory data were obtained by using standard techniques. Blood was collected immediately before the second dialysis session of the week. Hematological data were accessed by using an automatic blood cell counter (Sysmex K1000; Sysmex, Germany). Differential leukocyte and reticulocyte counts were performed by microscopy. Serum iron concentration was determined using a colorimetric method (Iron, Randox Laboratories Ltd., North Ireland, UK), whereas serum ferritin and transferrin were measured by immunoturbidimetry (Ferritin, Laboratories Ltd., North Ireland, UK; Transferrin, Laboratories Ltd., North Ireland, UK). Serum C-reactive protein (CRP) was determined by nephelometry [CRP (latex) HighSensitivity, Roche Diagnostics].

The study was approved by the Ethic Committee of the Institute of Health Sciences of Portuguese Catholic University. All patients gave written informed consent to participate in this study. The study was conducted in accordance with the Declaration of Helsinki. 
Table 1. Clinical data, hematological and biochemical data, nutritional markers and dialysis adequacy for total ESRD patients on OL-HDF, according to age (quartiles)

\begin{tabular}{|c|c|c|c|c|c|}
\hline & $\begin{array}{l}\text { ESRD patients } \\
\text { 1st quartile } \\
(<56 \text { years old }) \\
(n=77)\end{array}$ & $\begin{array}{l}\text { ESRD patients } \\
2^{\text {nd }} \text { quartile } \\
(57-68 \text { years old }) \\
(n=86)\end{array}$ & $\begin{array}{l}\text { ESRD patients } \\
3^{\text {rd }} \text { quartile } \\
(69-75 \text { years old }) \\
(n=70)\end{array}$ & $\begin{array}{l}\text { ESRD patients } \\
4^{\text {th }} \text { quartile } \\
(>75 \text { years old }) \\
(n=72)\end{array}$ & $\begin{array}{l}\text { P value } \\
\text { (ANOVA } \\
\text { analysis) }\end{array}$ \\
\hline \multicolumn{6}{|c|}{ Clinical data, and dialysis adequacy markers } \\
\hline CVC use, n (\%) & $14(17.1)$ & $18(20.5)$ & $11(15.3)$ & $26(34.2)$ & \multirow[b]{2}{*}{$0.02 \#$} \\
\hline AVF use, n (\%) & $68(82.9)$ & $70(79.5)$ & $61(84.7)$ & $50(65.8)$ & \\
\hline Diabetic patients, n (\%) & $21(25.6)$ & $35(39.7)$ & $33(45.8)$ & $27(35.5)$ & $0.04 \#$ \\
\hline Hypertensive patients, n (\%) & $16(19.5)$ & $9(10.2)$ & $10(13.9)$ & $11(14.4)$ & $0.40 \#$ \\
\hline Previous time on dialysis, months & $73.45(153.70)$ & $59.24(100.67)$ & $64.53(139.66)$ & $58.13(91.28)$ & 0.85 \\
\hline URR, \% & $76.75(5.08)$ & $76.99(5.93)$ & $76.34(6.64)$ & $76.93(7.56)$ & 0.92 \\
\hline KT/Ve & $1.55(0.34)$ & $1.54(0.32)$ & $1.47(0.25)$ & $1.55(0.38)$ & 0.41 \\
\hline Creatinine, mg/dL & $9.16(2.81)$ & $7.88(2.92)$ & $7.14(2.76)$ & $6.22(2.41)$ & $<0.001$ \\
\hline Darbepoeitin, $\mu \mathrm{g} / \mathrm{kg} /$ week & $0.32(0.43)$ & $0.41(0.69)$ & $0.39(0.44)$ & $0.36(0.40)$ & 0.70 \\
\hline \multicolumn{6}{|c|}{ Hematological data } \\
\hline Hemoglobin, g/dL & $11.67(1.46)$ & $11.61(1.44)$ & $11.69(1.20)$ & $11.56(1.38)$ & 0.93 \\
\hline Hematocrit, \% & $35.70(4.50)$ & $35.81(4.37)$ & $36.24(3.74)$ & $35.88(4.31)$ & 0.88 \\
\hline Erythrocytes, x10 ${ }^{12} / \mathrm{L}$ & $3.75(0.49)$ & $3.77(0.54)$ & $3.85(0.45)$ & $3.74(0.52)$ & 0.56 \\
\hline MCV, fl & $95.47(5.46)$ & $95.61(5.87)$ & $94.46(5.81)$ & $96.31(6.10)$ & 0.28 \\
\hline MCH, pg & $31.21(2.01)$ & $30.27(5.05)$ & $30.05(4.17)$ & $30.99(2.14)$ & 0.13 \\
\hline MCHC, g/dL & $32.69(0.97)$ & $32.39(1.12)$ & $32.26(1.16)$ & $32.18(1.08)$ & 0.20 \\
\hline RDW, \% & $14.60(1.50)$ & $14.46(1.36)$ & $14.93(1.49)$ & $14.99(1.64)$ & 0.30 \\
\hline White blood cells, $\times 10^{9} / \mathrm{L}$ & $6.76(1.95)$ & $6.26(1.81)$ & $7.17(2.78)$ & $6.65(2.79)$ & 0.11 \\
\hline Neutrophil/Lymphocyte ratio & $2.68(1.62)$ & $2.98(1.42)$ & $2.90(1.27)$ & $2.84(1.29)$ & 0.55 \\
\hline \multicolumn{6}{|c|}{ Iron status } \\
\hline Iron, $\mathrm{mg} / \mathrm{dL}$ & 74.53 (31.99) & $74.91(33.09)$ & $63.04(24.52)$ & $61.91(23.51)$ & 0.01 \\
\hline Transferrin, mg/dL & $194.26(43.18)$ & $209.59(121.84)$ & $185.62(40.21)$ & $204.12(97.38)$ & 0.31 \\
\hline Transferrin saturation, $\%$ & $28.94(14.81)$ & $30.34(13.80)$ & $25.23(11.53)$ & $24.47(9.64)$ & 0.01 \\
\hline Ferritin, ng/mL & $355.69(213.85)$ & $430.21(238.55)$ & $408.79(267.16)$ & $413.11(239.42)$ & 0.22 \\
\hline \multicolumn{6}{|c|}{ Inflammatory markers } \\
\hline CRP, mg/dL & $6.53(11.28)$ & $10.02(18.36)$ & $13.77(19.67)$ & $8.72(12.04)$ & 0.13 \\
\hline \multicolumn{6}{|c|}{ Nutritional markers } \\
\hline Albumin, g/dL & $45.04(13.61)$ & $43.59(10.52)$ & $41.57(7.92)$ & $39.37(8.01)$ & 0.01 \\
\hline $\mathrm{BMI}, \mathrm{Kg} / \mathrm{m}^{2}$ & $24.80(4.33)$ & $26.46(5.05)$ & $26.54(4.08)$ & $24.82(4.08)$ & 0.01 \\
\hline nPCR, g/kg/day & $1.51(0.75)$ & $1.43(0.61)$ & $1.34(0.62)$ & $1.17(0.35)$ & 0.01 \\
\hline
\end{tabular}

Results are presented as mean (SD). \# chi-squared test or Fisher's exact test. CVC: central venous catheter; AVF: arteriovenous fistula; URR: urea reduction ratio; MCV: mean cell volume; $\mathrm{MCH}$ : mean cell hemoglobin; MCHC: mean cell hemoglobin concentration; RDW: red blood cell distribution width; CRP: C-reactive protein; BMI: body mass index; nPCR: normalized protein catabolic rate.

\section{Kidney Disease Quality of Life Questionnaire-Short Form}

KDQOL-SF became the most widely used QOL measure for ESRD patients. It was developed in the United States of America for dialysis patients [16], and has been translated into several languages, to be used in several large studies involving dialysis patients [17-19]. In the present work, HRQOL was assessed with the validated instrument KDQOL-SF version 1.3 for Portuguese population [20]. This query was given to the patients at starting of the dialysis session, and they were helped to fill out the forms, if necessary. 


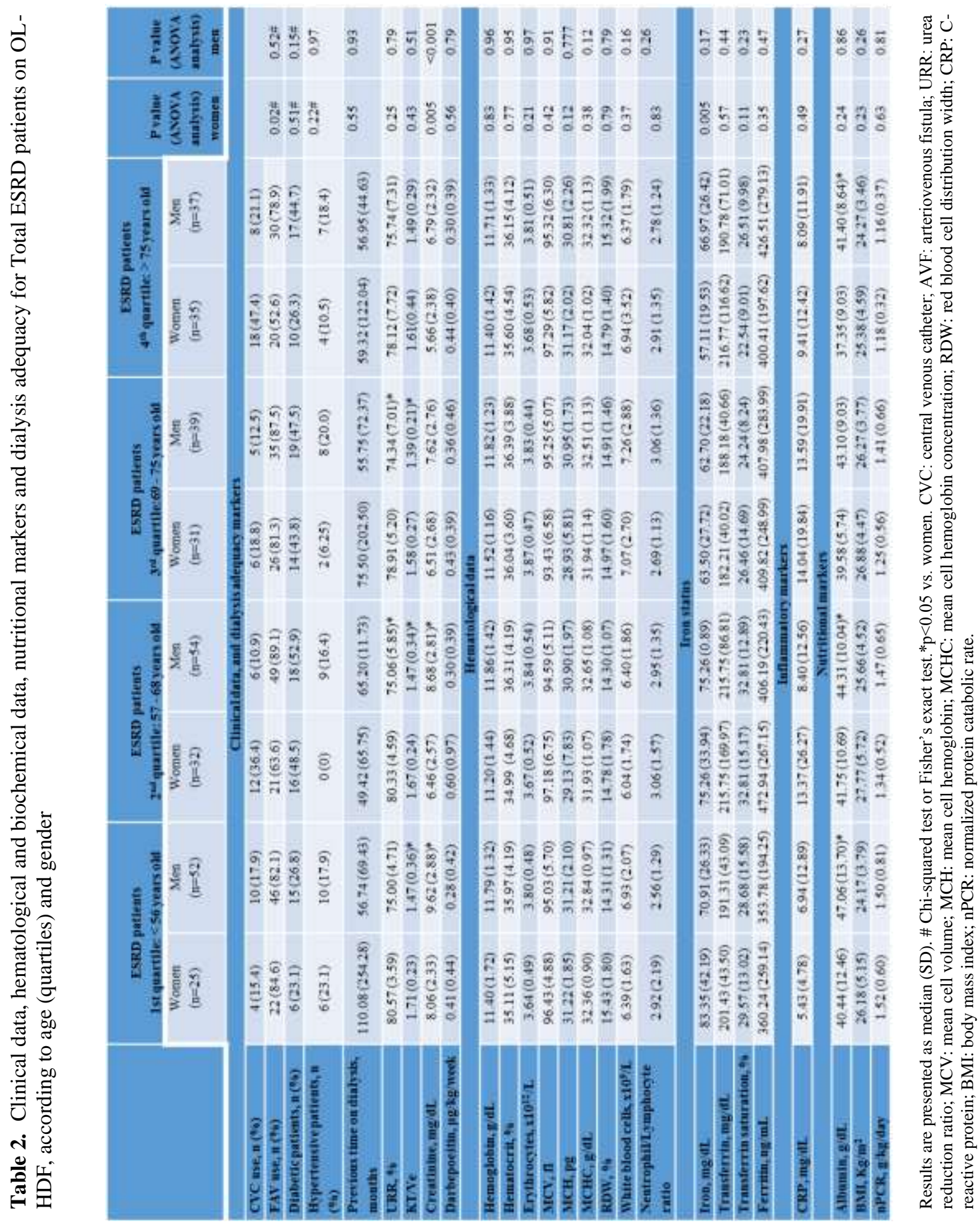


The KDQOL-SF can be divided in a generic part and in a disease-specific part. The generic part is formed by the Short Form (SF-36, version 2). The SF-36 has 8 domains: the patient's physical functioning (10 items); role physical (4 items); pain (2 items); general health (5 items), emotional well-being (5 items); role-emotional (3 items); social functioning ( 2 items); and energy and fatigue (4 items) [20,21]. The disease-specific part of the KDQOL-SF consists of 43 kidney disease-targeted questions. The responses to these items are condensed in 11 domains: symptom/problems (12 items), effects of kidney disease (8 items), burden of kidney disease (4 items), work status ( 2 items), cognitive function (3 items), quality of social interaction (3 items), sexual function (2 items), sleep (4 items), social support (2 items), staff encouragement ( 2 items) and patient satisfaction ( 1 item). This group of questions covers different domains to face the multidimensional nature of HRQOL-SF. These domains have a score from 0 to 100 , with higher scores indicating a better quality of life, or the absence of problems.

Table 3. HRQOL results based on the KDQOL-SF instrument for ESRD patients on OL-HDF, according to age (quartiles)

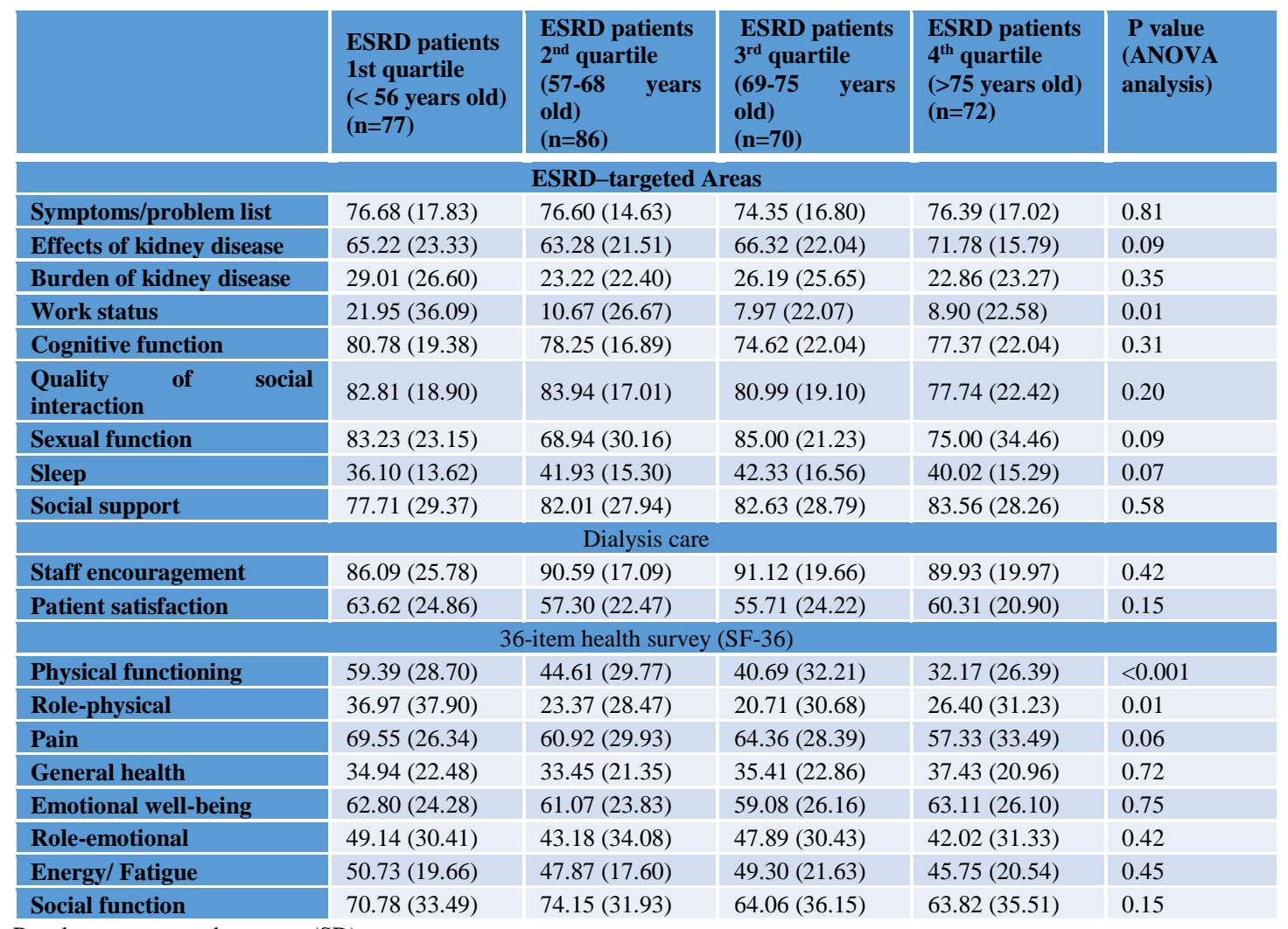

\section{Statistical analysis}

All variables are reported as mean \pm standard deviation or as proportions. Data were analyzed using the program SPSS 20.0 for Windows (SPSS, Inc., Chicago, IL). The Normality of data was tested using the KolmogorovSmirnov test. Multiple comparisons between groups were performed by one-way ANOVA supplemented with Tukey's HSD Post Hoc test. Differences between groups were analyzed by using Student t-test or Mann-Whitney test, according to the results obtained in the Kolmogorov-
Smirnov test. The association between categorical variables was analyzed using the chi-squared test or Fisher's exact test. Pearson's rank correlation coefficient was used to evaluate relationships between sets of data. $\mathrm{P}<0.05$ was accepted as statistically significant.

\section{RESULTS}

The socio-demographic data, clinical features, dialysis adequacy, biochemical and hematological data, and nutritional markers of ESRD patients under OL-HDF, are 
presented in tables I and II, according to quartile of age and gender. The HRQOL results, based on the KDQOLSF instrument, are displayed in tables III and IV.

Analyzing the results according to quartiles of age, when considering all patients, we found that ESRD patients with less than 56 years (1st quartile) presented a significantly lower proportion of diabetic patients, increasing this proportion with age. A significant decrease with age was observed for serum levels of creatinine, iron, transferrin saturation, albumin and nPCR. Concerning to body mass index (BMI), we also found significant differences between age groups, with patients in the second and third quartiles presenting higher BMI values (Table I).

Table 4. HRQOL results based on the KDQOL-SF instrument for ESRD patients on OL-HDF, according to age (quartiles) and gender.

\begin{tabular}{|c|c|c|c|c|c|c|c|c|c|c|}
\hline & \multicolumn{2}{|c|}{$\begin{array}{l}\text { ESRD patients } \\
\text { Iat auartile: } 56 \text { vers ohf }\end{array}$} & \multicolumn{2}{|c|}{$\begin{array}{l}\text { ESRO patients } \\
2^{-4} \text { quartifini } 57 \text { - } 6 \text { d vears ol }\end{array}$} & \multicolumn{2}{|c|}{ 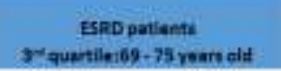 } & \multicolumn{2}{|c|}{$\begin{array}{l}\text { ESRD patiants } \\
\text { 4h quartilei }>75 \text { yeas old }\end{array}$} & \multirow{2}{*}{$\begin{array}{l}\text { Pvalue } \\
\text { aAvonA } \\
\text { analysia) } \\
\text { wamen }\end{array}$} & \multirow{2}{*}{$\begin{array}{l}\text { Pyolas } \\
\text { [Anova } \\
\text { analyaha] } \\
\text { min }\end{array}$} \\
\hline & $\begin{array}{l}\text { Womien } \\
\{m=25\}\end{array}$ & $\operatorname{Min}_{(m-52)}$ & $\begin{array}{l}\text { Women: } \\
(n=32)\end{array}$ & $\operatorname{Men}_{|n \rightarrow 54\rangle}$ & $\begin{array}{l}\text { Wornen } \\
\text { in=31| }\end{array}$ & $\begin{array}{c}\text { Men } \\
\{n=39\}\end{array}$ & $\begin{array}{l}\text { Womien } \\
(n=35)\end{array}$ & $\operatorname{men}_{(n=37)}$ & & \\
\hline \multicolumn{11}{|c|}{ ESRD-tergeted Aress } \\
\hline Symptams/protiemilist & $7413(2769)$ & 7783417.941 & 69.65117 .291 & $\left.80.1111161\right|^{*}$ & $30.31(13.22)$ & $77.74(18.81)^{\circ}$ & $71: 14(1796)$ & $81.09(14.84)^{\circ}$ & 0.77 & 0.69 \\
\hline tffects of hidney disesse & $53.07(22.60)$ & $66.07\{24.11\}$ & $38.43\{23.90\}$ & $65.50\{20.03)$ & $63.23(21.19)$ & $68.83(22.67)$ & 69994\{1496\}) & $73.57\{10.56\}$ & 0.22 & 0.31 \\
\hline Burden of kidhey diseose & $31.25(26.45)$ & $2807126: 891$ & $28007268 a !$ & $17.38(18.93)$ & $20.83(21.57)$ & $30.43(27.96)$ & $21.61(22.86)$ & 24.01123 .901 & 0.14 & 0655 \\
\hline Cognitive function & $76.11(19.11)$ & 82.83119 .311 & 7598 (18.99) & 79.32 |15.98\} & $70.04(25.10)$ & $78.32(18.7)$ & $73.91(22.93)$ & $81.02\{20.83\}$ & 0.67 & 0.67 \\
\hline Qualty of sodal imtoraction. & $8236(20.81)$ & $82.99(18.22\}$ & $81003\{1581\}$ & 105.41 (17.65) & 80.32 (18.31) & $81.52(19.92\}$ & $70.70(23.62)$ & $84.60(19.20)^{\circ}$ & 0.68 & 0,76 \\
\hline Sexual function & $76.39(28.26)$ & $85.16|21.64|$ & $65.63(3180)$ & $68.75\{30.177$ & $72.50(25.62)$ & $91.25(16.72)$ & $100.00(0.00)$ & 62.50936 .801 & ase & 0.25 \\
\hline Sleep & 37.31 (15.94) & As $55(12,5)$ & $4535(24.00)$ & $40.12\{15.30\}$ & $43.89(11.80)$ & $41,13(19 ., 49)$ & $43.65(1707)$ & $36.58\{12.68\}$ & 0.18 & 0.21 \\
\hline Social suppont & $71.15\{35.76\}$ & $80.70\{25.74\}$ & $82.83 \mid 28.71\}$ & $01.17(27.85)$ & $81.18(30.04)$ & $83.75(28.19)$ & $88.89(2488)$ & $7838|30.65|$ & 0.14 & 0.86 \\
\hline \multicolumn{11}{|c|}{ Diglysectere } \\
\hline Steff encpurverement & $88.94(23.27)$ & $84.72\{27.00\}$ & $90.53(10.25)$ & $90.45(17,8)$ & 95.5638 .87 & $87.50(24.83)$ & $88.89(2252)$ & $50.97(17.32)$ & 0.44 & $0.4 \mathrm{e}$ \\
\hline Patient satifaction & $71.79(2399)$ & $59.82124 .577^{\circ}$ & $5758 \mid 23.60\}$ & $56.36\{21,39\}$ & $58.33(21.589$ & $53.51(26.32)$ & $58.77(1721)$ & $61.24[24.17]$ & 0.04 & 0.41 \\
\hline \multicolumn{11}{|c|}{$36-$ tam health surver (SF-36) } \\
\hline Rolo.physical & $35.58(37.24)$ & $37.52\{38.52\}$ & $16.41\{25,39\}$ & $27.51:(29,77)^{*}$ & $13.67(20.60)$ & $26.64(36.32)^{*}$ & $26.32(33.49)$ & 26.48 (29.25) & 0.02 & 0.27 \\
\hline Fain & $60.19(29.15)$ & $73.82(24.03)^{\circ}$ & $4930 \mid 33.11$ ) & $67.36(25.89)^{*}$ & $52.06(30.09)$ & $74.39122 .75)^{*}$ & aros(34 39) & orss(29sa) & 0.42 & 0.37 \\
\hline Geteralhealth & $32.24\{21.48\}$ & 36.14123 .001 & $28.24(22.41)$ & $36.52\{21.08\}$ & $27.13(10.05)$ & 42.22 (23.69)* & $35.97(24.85)$ & $38.84 \mid 16.55\}$ & 0.32 & 0.52 \\
\hline Imetianal well-beine. & $58.09(2533)$ & $64.92,23,73 \mid$ & $53.48(20.71)$ & $65.82|24.72|^{\circ}$ & $52.50(26.61)$ & $64.49(24.84)$ & $59.72(26.62)$ & $6672(25.54)$ & 0.58 & D.9a \\
\hline Role-emotional & $40.51(30.40)$ & $53.2129 .83\}$ & 36.57 (35.36) & $47.30\{32.93\}$ & $38.54(28.62)$ & $55.56\left\{\left.30.06\right|^{*}\right.$ & 41.58 (33. ot) & $42.46 \mid 29.99]$ & 0.92 & 0,21 \\
\hline fnerge/ Fatigue & $49.80[20967$ & $51.23|19.23|$ & $44.70|17.04|$ & 49.55117 .911 & $42.34(21.74)$ & $55.00\langle 20.07\}^{*}$ & $44.72(2097)$ & 46.76120 .351 & 0.60 & 0.29 \\
\hline Social funttian & $66.83\{34.60\}$ & 72.59132 .941 & 68.75 (35.50) & $7750(29.79)$ & 59.77 (38. .5) & $67.50(33.04)$ & $57.57(37289$ & $7007(32.95)$ & 0.54 & 0.47 \\
\hline
\end{tabular}

Results are presented as mean (SD).*p<0.05 vs. women.

When we analyzed data separately, for men and women, we found that both presented a similar pattern, with decreasing levels of creatinine with age; a significant decrease in iron serum levels was observed only in men, according to age. When we compared the results for men and women in each age quartile, we found that men, in the first quartile, presented significantly higher values of creatinine and albumin, and a significantly lower KT/Ve; in the second quartile, men presented a significantly lower URR and KT/Ve, and, as occurred for those men in the 1st quartile, significantly higher values of creatinine and albumin; in the third quartile, men still presented significantly lower values of URR and KT/Ve; and, in the last quartile, we only found significantly lower values of albumin, in men (Table II).

Concerning to HRQOL, the use of KDQOL-SF instrument, showed significant differences for work status, physical functioning and role-physical, which decreased with increasing age (table III), when considering all patients. When we analyzed the results by gender, we found a decrease in work status, patient satisfaction and role-physical, in women with more than 56 years of age. In men, we found significant differences in physical functioning, decreasing with increasing age. When we compared the results between men and women in each age quartile, we found that men, in the first quartile, presented a significant increase in physical functioning and pain, and a significantly higher values of patient's satisfaction; in the second quartile, men presented significantly higher values of symptoms/problem list, work status, physical functioning, role physical, pain and emotional well-being; in the third quartile, men presented significantly higher values of symptoms/problem list, work status, role physical, pain, general health, role-emotional and energy/fatigue; in the last quartile, men presented significantly higher values of symptoms/problem list, quality of social interactions and of pain (Table IV). 

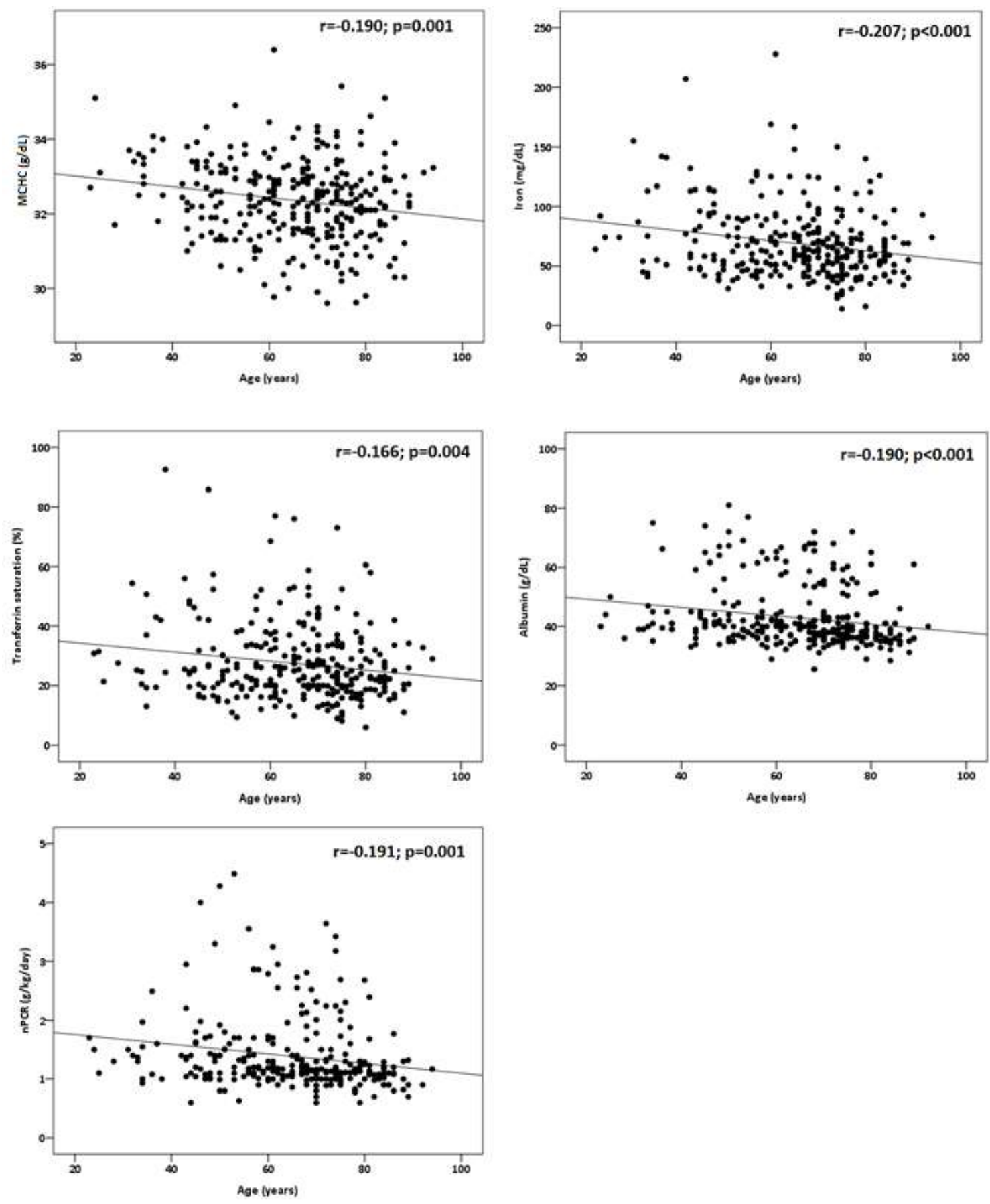

Figure 1. Correlations between age and MCHC, iron, transferrin saturation, albumin and nPCR in ESRD patients.

Considering all ESRD patients, significant negative correlations were found between age and $\mathrm{MCHC}$, iron, transferrin saturation, albumin, nPCR (Fig. 1), work status $(\mathrm{r}=-0.199 ; \mathrm{p}<0.001)$, physical functioning $(\mathrm{r}=-0.323$; $\mathrm{p}<0.001)$ and role-physical $(\mathrm{r}=-0.182 ; \mathrm{p}=0.001)$.

\section{DISCUSSION}

The dialysis therapy in ESRD has a considerable impact on functional status and in the quality of life of the patients, as it is, usually, accompanied by symptoms that affect daily life. Indeed, it seems that HRQOL is more 
important for the patient than its own survival [5]. Therefore, we figured as important to evaluate the patient's perception of HRQOL and to identify the variables that might underlie worsening of the quality of life of these patients $[22,23]$. As the prevalence of ESRD increases with age, we studied the perception of HRQOL in ESRD patients under OL-HDF therapy, according to age, and also according to gender. Besides the HRQOL as perceived by the patients, we gathered socio-demographic data, clinical features and several analytical studies of the patients.

Our study showed that increasing age in ESRD patients is associated with a decrease in physical functioning, role-physical and work status; physical functioning presented a progressive decrease with age, while work status and role-physical decreased progressively from the first to the third quartile of age, and remained almost constant afterwards, suggesting that the perception of the patients about its own physical capacities changes after the age of 75 years, probably because their target pattern for physical activity becomes lower. A similar perception was found in women patients; they also presented a significant decrease in patient's satisfaction, after the age of 57 years. Men's perception of HRQOL was more favorable, as only a significant decrease in physical functioning was found with increasing age.

When we compared the HRQOL for men and women, in each quartile of age, men presented significantly increased values in several domains, some showing an improvement in their perception of HRQOL, namely, work status, quality of social interaction, physical functioning, general health, role emotional, and others reflecting a worst perception of HRQOL, as symptoms problem list and pain. These changes are particularly evident for patients 57 to 75 years old. Actually there are no differences between the perception of HRQOL for older men and women, above 75 years old. The more negative disease perception of women might be associated with the increased prevalence of depression in women. Moreover, a lower social status, lower education, worst financial situation, or lack of employment that have been consistently associated with impaired HRQOL [24, 25], are usually more frequent in women, which could also contribute to the differences observed in HRQOF for men and women.

Along with the decrease in physical domains of HRQOL with aging, we found a decrease in creatinine serum levels and in nutritional status. Indeed, aging is associated with loss of skeletal muscle mass, contributing to the decrease in creatinine serum levels, observed with aging. There are reports in literature showing that older dialysis patients present a higher risk of developing energy-protein malnutrition [26,27], which are in accordance with our results showing a progressive decrease in nutritional markers (albumin serum levels and nPCR), with increasing age. However, BMI did not follow the same pattern, as it was higher in the second and third quartile of age, as compared to the first and fourth quartiles of age. Actually, it has been reported that a higher BMI in ESRD patients on dialysis is paradoxically protective and associated with improved survival, while lower BMI has been associated with increased mortality [28-31]. These findings have been referred as a "reverse epidemiology". Indeed, a high BMI is a risk factor for the development and progression of CKD; however, it seems that there are some mechanisms that protect ESRD patients with higher BMI, as compared to those with lower BMI $[32,33]$.

It is known that ESRD patients develop an anemia, which is mainly due to the incapacity of the kidneys to produce erythropoietin, the hormone regulator of erythrocyte production. The anemia is corrected by administration of recombinant human erythropoietin to achieve the target values of hemoglobin 11-12 $\mathrm{g} / \mathrm{dl}$. The hemoglobin concentration of these ESRD patients shows that most of them reached those target hemoglobin concentrations, and the values are similar, independently of age and gender. However, concerning iron status, we found a significant decrease in seric iron and transferrin saturation, with age. The rhEPO needs to maintain hemoglobin values present a trend towards increasing values with age, in spite of the increased values of iron storage that could be used for erythropoiesis; moreover a trend towards a lower mean cell hemoglobin concentration, further suggests an increasing disturbance in iron metabolism [34]. Actually, a significant negative correlation was found between age and $\mathrm{MCHC}$, seric iron and transferrin saturation, further strengthening the development of a disturbance in iron metabolism with increasing age of ESRD patients. Considering that women present, independently of age quartile, a lower $\mathrm{MCHC}$, the fatigue and other associated features of anemia, might contribute to the more negative perception of HRQOL observed in women.

A significant negative correlation was found in both, women and men, between age and markers of dialysis adequacy (urea, URR and KTVe), suggesting that aging is associated with a decrease in dialysis adequacy, in accordance with previous reports [35,36]. Dialysis adequacy markers are not independent variables, as they are influenced by protein intake and body composition. As already referred, ESRD patients present a weaker nutritional status with increasing age that may underlie the reduction in dialysis adequacy. Indeed, a significant 
negative correlation was found between age and albumin concentration and nPCR.

As previously reported [37-39], aging is associated with increased use of central venous catheter (CVC), particularly in women. Higher age and female gender are independently associated with the use of CVC rather than with arteriovenous fistula (AVF), at starting dialysis. The underlying reasons for these findings are poor clarified; however, there is evidence that female gender and advanced age are associated with shorter duration of primary vascular access patency [40]. Moreover, dialysis flow rates achieved by AVF in men seems to provide a greater benefit over catheters, compared with the benefit achieved in women, as CVC-related infections and other complications are more common and/or severe in men.

We also found that aging is associated with an increase in the proportion of diabetic patients, which decreased in the last quartile of age. In fact, it is well known that the prevalence of diabetes increases significantly with age [41]. The reduction of diabetes in ESRD patients with more than 75 years of age is, probably, explained by the high mortality observed in diabetic ESRD patients, usually due to cardiovascular events [42].

In conclusion, our data show that aging is associated with worsening of patient's perception of HRQOL, namely, in work status, physical functioning and rolephysical, and this is particularly negative for women. These changes in patient's perception was linked to a decrease in nutritional status that might underlie the reduction in dialysis adequacy, a disturbance in iron metabolism that seems to compromise iron availability, worsening anemic features and HRQOL of ESRD patients. The knowledge of these changes associated with aging, which have impact in the quality of life of the patients, could be useful in their management.

\section{References}

[1] Vollmer WM, Wahl PW, Blagg CR (1983). Survival with dialysis and transplantation in patients with endstage renal disease. N Eng J Med, 308:1553-1558.

[2] Held PJ, Brunner F, Odaka M, Garcia JR, Port FK, Gaylin DS (1990). Five-year survival for end-stage renal disease patients in the United States, Europe, and Japan, 1982 to 1987. Am J Kidney Dis, 15:451-457.

[3] Jager KJ, Lindholm B, Goldsmith D, Fliser D, Wiecek A, Suleymanlar G, et al. (2011). Cardiovascular and non-cardiovascular mortality in dialysis patients: where is the link. Kidney Int,1 (suppl 1): 21-23.

[4] Foley RN, Parfrey PS, Sarnak MJ (1998). Clinical epidemiology of cardiovascular disease in chronic renal disease. Am J Kidney Dis, 32(suppl 3): S112-119.
[5] Mazairac HA, de Wit GA, Grooteman MPC, et al (2012). Clinical Performance Targets and Quality of Life in Hemodialysis Patients. Blood Purif, 33:73-79.

[6] Mapes DL, Lopes AA, Satayathum S, et al. (2003). Health-related quality of life as a predictor of mortality and hospitalization: the Dialysis Outcomes and Practice Patterns Study (DOPPS). Kidney Int, 64:339-349.

[7] Lowrie EG, Curtin RB, Lepain N, Schatell D (2003). Medical outcomes study short form-36: a consistent and powerful predictor of morbidity and mortality in dialysis patients. Am J Kidney Dis, 41: 1286-1292.

[8] Knight EL, Ofsthun N, Teng M, Lazarus JM, Curhan GC (2003). The association between mental health, physical function, and hemodialysis mortality. Kidney Int 63:1843-1851.

[9] Germin-Petrović D, Mesaros-Devcić I, Lesac A, Mandić M, Soldatić M, Vezmar D, Petrić D, Vujicić B, BasićJukić N, Racki S (2011). Original scientific paper Health-related Quality of Life in the Patients on Maintenance Hemodialysis: The Analysis of Demographic and Clinical Factors Antropol, 35: 687693.

[10] Gibbons E, Fitzpatrick R (2010). A Structured review of patient-reported outcome measures for people with chronic kidney disease. Report to the Department of Health and NHS Kidney Care, University of Oxford.

[11] Schmid H, Schiffl H (2012). Hemodiafiltration and survival of end-stage renal disease patients: the long journey goes on. Int Urol Nephrol, 44:1435-1440.

[12] Maduell F, Moreso F, Pons M, Ramos R, Mora-Macià J, Carreras J, Soler J, Torres F, Campistol JM, MartinezCastelao A, for the ESHOL Study Group (2013). HighEfficiency Postdilution Online Hemodiafiltration Reduces All-Cause Mortality in Hemodialysis Patients. J Am Soc Nephrol, 24:487-497.

[13] Mazairac AH, de Wit GA, Grooteman MP, et al. (2013). Effect of hemodiafiltration on quality of life over time. Clin J Am Soc Nephrol, 8:82-89.

[14] Franco MR, Fernandes NM (2013). Diálise no paciente idoso: um desafio do século XXI - revisão narrativa. J Bras Nefrol, 35:132-141.

[15] Laudański K, Nowak Z, Niemczyk S (2013). Agerelated differences in the quality of life in end-stage renal disease in patients enrolled in hemodialysis or continuous peritoneal dialysis. Med Sci Monit, 19:378385.

[16] Rebollo P, Ortega F, Baltar JM et al. (1998). Healthrelated quality of life HRQOL in end stage renal disease ESRD patients over 65 years. Geriatr Nephrol Urol, 8: 85-94.

[17] Hays RD, Kallich JD, Mapes DL, Coons SJ, Carter WB (1994). Development of the kidney disease quality of life (KDQOL) instrument. Qual Life Res, 3:329-338.

[18] Mapes DL, Bragg-Gresham JL, Bommer J, et al. (2004). Health-related quality of life in the Dialysis Outcomes and Practice Patterns Study (DOPPS). Am J Kidney Dis, 44(suppl 2):54-60.

[19] Unruh M, Benz R, Greene T, et al. (2004). Effects of hemodialysis dose and membrane flux on health-related 
quality of life in the HEMO Study. Kidney Int, 66:355366.

[20] Ferreira PL, Anes EJ (2010). Medição da qualidade de vida de insuficientes renais crónicos: criação da versão portuguesa do KDQOL-SF. Rev Port Sau Pub, 28: 3139.

[21] Lessan-Pezeshki M, Zohreh Rostami (2009). Contributing Factors in Health-Related Quality of Life Assessment of ESRD Patients: A Single Center Study. Int J Nephrol Urol, 1:129-136.

[22] Anees M, Hameed F, Mumtaz A, Ibrahim M, Saeed KhanMN (2011). Dialysis-Related Factors Affecting Quality of Life in Patients on Hemodialysis. Iran J Kidney Dis, 5:9-14.

[23] Knight EL, Ofsthun N, Teng M, Lazarus JM, Curhan GC (2003). The association between mental health, physical function and hemodialysis mortality. Kidney Int, 63:1843-1851.

[24] Simmons RG, Abress L (1990). Quality-of-life issues for end-stage renal disease patients. Am J Kidney Dis, 15:201-208.

[25] Kalantar-Zadeh K, Fouque D, Kopple JD (2004). Outcome research, nutrition, and reverse epidemiology in maintenance dialysis patients. J Ren Nutr, 14:64-71.

[26] Schiffl H (2007). Prospective randomized cross-over long-term comparison of online haemodiafiltration and ultrapure high-flux haemodialysis. Eur J Med Res, 12:26-33.

[27] Cuevas X, García F, Martín-Malo A, Fort J, Lladós F, Lozano J, Pérez-García R (2011). Risk Factors Associated with Cardiovascular Morbidity and Mortality in Spanish Incident Hemodialysis Patients: Two-Year Results from the ANSWER Study. Blood Purif, 33:21-29.

[28] Yen TH, Lin JL, Lin-Tan DT, Hsu CW (2010). Association between body mass and mortality in maintenance hemodialysis patients. Ther Apher Dial, 14:400-408.

[29] Tanner RM, Brown TM, Muntner P (2012). Epidemiology of Obesity, the Metabolic Syndrome, and Chronic Kidney Disease. Curr Hypertens Rep, 14:152159.

[30] Kalantar-Zadeh K, Abbott KC, Salahudeen AK, Kilpatrick RD, Horwich TB (2005). Survival advantages of obesity in dialysis patients. Am J Clin Nutr, 81:543554.

[31] Kalender B, Ozdemir AC, Dervisoglu E, Ozdemir O (2007). Quality of life in chronic kidney disease: effects of treatment modality, depression, malnutrition and inflammation. Int J Clin Pract, 61:569-576.

[32] Tanner RM, Brown TM, Muntner P (2012). Epidemiology of Obesity, the Metabolic Syndrome, and Chronic Kidney Disease. Curr Hypertens Rep, 14:152159.

[33] Kalantar-Zadeh K, Abbott KC, Salahudeen AK, Kilpatrick RD, Horwich TB (2005). Survival advantages of obesity in dialysis patients. Am J Clin Nutr, 81:543554.
[34] Costa E, Fernandes J, Ribeiro S, Sereno J, Garrido P, Rocha-Pereira P, Coimbra S, Catarina C, Belo L, Bronze-da-Rocha E, Vala H, Alves R, Reis F, SantosSilva A (2014). Aging is Associated with Impaired Renal Function, INF-gamma Induced Inflammation and with Alterations in Iron Regulatory Proteins Gene Expression. Aging Dis, in press.

[35] Seica A, Segall L, Verzan C et al. (2009). Factors affecting the quality of life of haemodialysis patients from Romania: a multicentric study. Nephrol Dial Transplant, 24: 626-629.

[36] Mapes DL, Bragg-Gresham JL, Bommer J, et al. (2004). Health-related quality of life in the Dialysis Outcomes and Practice Patterns Study (DOPPS). Am J Kidney Dis, 44(suppl 2):54-60.

[37] Astor BC, Coresh J, Powe NR, Eustace JA, Klag MJ (2000). Relation between gender and vascular access complications in hemodialysis patients. Am J Kidney Dis, 36: 1126-1134.

[38] Stehman-Breen CO, Sherrard DJ, Gillen D, Caps M (2000). Determinants of type and timing of initial permanent hemodialysis vascular access. Kidney Int, 57: $639-645$.

[39] Astor BC, Eustace JA, Powe NR, Klag MJ, Sadler JH, Fink NE, Coresh J (2001). Timing of nephrologist referral and arteriovenous access use. The CHOICE Study. Am J Kidney Dis, 38:494-501.

[40] Ng YY, Wu SC, Hung YN, Ko PJ (2009). Effect of demographic characteristics and timing of vascular access maturation on patency in Chinese incident haemodialysis patients. Nephrol Dial Transplant, 11:3447-3453.

[41] van Blijderveen JC, Straus SM, Zietse R, Stricker BH, Sturkenboom MC, Verhamme KM (2013). A population-based study on the prevalence and incidence of chronic kidney disease in the Netherlands. Int Urol Nephrol, 46:583-592

[42] Shoji T, Emoto M, Shinohara K, Kakiya R, Tsujimoto Y, Kishimoto H, Ishimura E, Tabata T, Nishizawa Y (2001). Diabetes mellitus, aortic stiffness, and cardiovascular mortality in end-stage renal disease. J Am Soc Nephrol, 12:2117-2124. 